\title{
Lutfianto
}

\section{TARJAMAH AYAT-AYAT AL-QURAN DENGAN TEMBANG MACAPAT DALAM WAYANG KEKAYON KHALIFAH YOGYAKARTA}

\author{
Universitas Islam Negeri Sunan Kalijaga, Yogyakarta \\ Email: lootfie80@gmail.com
}

Received:

2020-03-09

Received in revised form:

2020-05-22

Accepted:

2020-06-29

Citation:

Lutfianto, (2020),

Tarjamah Ayat-Ayat Al-

Quran Dengan Tembang

Macapat Dalam Wayang

Kekayon Khalifah

Yogyakarta, 7(1), 52-61.

\begin{abstract}
The Qur'an is kalamullah which contains great teachings and is conveyed in beautiful Arabic. This beanty can be approached by the beanty of the local language. For example in Java, the beauty of language in the Qur'an can also be felt when translated with a literary approach. One of them is literature that developed in Java, namely the art of song macapat. This macapat song art is used in the performance of Wayang Kekayon Khalifah Yogyakarta when translating the Qur'an. The author wants to present the translation of the Qur'an with macapat song that is in Wayang Kekayon Khalifah Yogyakarta. Macapat song in question is masumambang and pangkeur. It aims to belp readers understand the translation of the Qur'an with macapat song. The results showed that the translation of the Qur'an with the song of macapat presents the beauty and nuances of regionalism. Puppet Kekayon Khalifah Yogyakarta which presents a translation of the Qur'an with the song of macapat gives a new color to the universe of wayang. So that the Qur'an as a source of Islamic teachings can be delivered with wisdom.
\end{abstract}

Keywords: Wayang Kekayon Khalifah Yogyakarta, Al-Qur'an Translation, and Tembang Macapat. 


\begin{abstract}
Abstrak: Al-Quran adalah kalamullah yang didalamnya terkandung ajaran yang agung dan disampaikan dalam bahasa Arab yang indah. Keindahan ini bisa didekati dengan keindahan bahasa setempat. Contohnya di Jawa, keindahan bahasa dalam Al-Quran juga bisa dirasakan ketika diterjemabkan dengan pendekatan sastra. Salah satunya sastra yang berkembang di Jawa, yaitu seni tembang macapat. Seni tembang macapat ini dipakai dalam pagelaran Wayang Kekayon Khalifah Yogyakarta ketika menerjemabkan Al-Quran. Penulis ingin menghadirkan terjemah Al-Quran dengan tembang macapat yang ada dalam W ayang Kekayon Khalifah Yogyakarta. Tembang macapat yang dimaksud adalah maskumambang dan pangkur. Hal tersebut bertujuan untuk membantu pemahaman pembaca tentang terjemah Al-Quran dengan tembang macapat. Hasil penelitian menunjukkan bahwa terjemah Al-Quran dengan tembang macapat menghadirkan keindahan dan nuansa kedaerahan. Wayang Kekayon Khalifah Yogyakarta yang menghadirkan terjemahan AlQur'an dengan tembang macapat memberi warna baru dalam jagat pewayangan. Sebingga Al-Qur'an sebagai sumber ajaran islam dapat disampaikan dengan penub hikmah.
\end{abstract}

Kata kunci: Wayang Kekayon Khalifah Yogyakarta, Terjemah Al-Quran, dan Tembang Macapat.

\title{
PENDAHULUAN
}

Salah satu seni yang sudah lama ada dan diperhitungkan serta tetap terjaga adalah seni wayang. Wayang adalah seni yang mempunyai kesatuan seni dalam pagelarannya. Ada seni rupa, seni kriya, seni suara, seni sastra seni teater, seni music dan sebagainya. Sumarsam menyebut seni wayang menggunakan gaya bahasa sastra yang penuh dengan permainan suara dan memberikan efek psikologi yang mendalam bagi pendengarnya. ${ }^{1}$

Edukasi wayang dengan gaya bahasanya itu mempunyai peran penting dalam kehidupan masyarakat Jawa. Wayang seolah menjadi sarana transformasi social dalam kehidupan bermasyarakat. Wayang juga merupakan kesenian yang mengandung berbagai aspek kebudayaan. Maka tidak mengherankan jika wayang dipakai dalam pertunjukan yang mengedukasi/ mengajarkan etika dan moral dalam pendidikan non formal. ${ }^{2}$

\footnotetext{
${ }^{1}$ Sumarsam. Memaknai Wayang dan Gamelan: Temu Silang Jawa, Islam, dan Global (Yogyakarta: Gading, 2018), hlm. 9.

${ }^{2}$ Sunarto. Gendeng Dusun Kerajinan Wayang Kulit Purwa Yogyakarta Kelangsungan dan Perubahannya (Yogyakarta: Penerbit Lembaga Penelitian ISI Yogyakarta 2012), hlm. 37-38.
}

At-Turäs: Jurnal Studi Keislaman E-ISSN: 2460-1063, P-ISSN: 2355-567X Volume 7, No. 1, Januari-Juni 2020 
Meskipun wayang mempunyai bentuk dan varian yang cukup banyak namun pesan tentang edukasi tetaplah ada dalam setiap pertunjukan. Contohnya adalah wayang Suluh, wayang yang berisi sesuluh/ penerangan untuk mebangkitkan semangat perjuangan menghadapi Belanda saat itu. Ada lagi wayang kuluk yang mengambil kisah sejarah Kraton Ngayogyakarta. Ada juga wayang Dupara yang mengambil kisah problem-problem social abad ke-20. Wayang Jawa yang mengedukasi/ membuilding karakter seperti Pangeran Diponegara. Edukasi untuk anak-anak juga ada dalam Wayang Kancil. Termasuk juga edukasi tetnang agama Nasrani yang tertuang dalam Wayang Wahyu. ${ }^{3}$ Masih ada lagi wayang untuk edukasi falsafah Pancasila dan UUD 1945 yang mewujud dalam Wayang Pancasila. ${ }^{4}$

Bentuk wayang sebagai edukasi sangat dinamis bentuknya dari masa ke masa. Ada juga wayang Kekayon Khalifah Yogyakarta yang mengedukasi ajaran dengan mengutip ayat-ayat Al-Quran dan menerjemahkan dalam tembang macapat. Wayang ini menjadi unik ketika Al-Quran diterjemahkan dengan pendekatan tembang macapat. Seperti apa terjemahan ayat-ayat Al-Quran yang diterjemahkan dengan tembang macapat akan dibahas dalam tulisan berikut dengan deskriptif analisis.

\section{PEMBAHASAN}

Seni pertunjukan wayang mempunyai potensi untuk dijadikan sarana komunikasi dan transformasi informasi kepada masyarakat. Hal ini bisa menjadi sarana dakwah yang efektif baik pada jaman walisongo maupun pendakwah Islam masa kini. Seni pertunjukan bisa dipakai untuk penyebaran berbagai nilai, paham, konsep, gagasan, pandangan, dan ide yang bersumber dari agama Islam

\footnotetext{
${ }^{3}$ I Made Bandem dan Murgianto, Teater daerah di Indonesia (Yogyakarta: Kanisius, 1999), hlm. 12-13.

${ }^{4}$ Tim Senawangi, Ensiklopedi Wayang Indonesia (Jakarta: Penerbit Senawangi, 1999), hlm. 57. 
atau Al-Quran. Hal ini sesuai dengan ketetapan Sultan Demak pertama dengan walisongo menunjukan wayang tetap mempertimbangkan fiqh Islam dalam pembuatan dan pergelarannya. Cerita pewayangan tidak bertentangan dengan Tauhid. ${ }^{5}$

Wayang Kekayon Khalifah Yogyakarta hadir di abad 21 membawa misi dakwah/ edukasi ajaran Islam. Maka, Al-Quran sebagai sumber ajaran Islam akan diterjemahkan dengan pendekatan tembang macapat. Ayat-ayat suci AlQuran berbahasa Arab dengan sastra yang tinggi akan didekati dengan sastra Jawa. Sastra Jawa yang dimaksud adalah tembang macapat. Puisi tembang macapat, yaitu puisi Jawa tradisional yang terikat oleh kaidah-kaidah tertentu. Adapun nama-nama puisi tersebut adalah (1) dhandhanggula, (2) sinom, (3) asmaradana, (4) kinanthi, (5) pangkur, (6) durma, (7) pucung, (8) mijil, (9) maskumambang, (10) megatruh, (11) gambuh. Kaidah-kaidah tersebut adalah adanya gatra (jumlah baris), guru wilangan (jumlah suku kata), dhong-dhing (persajakan/ huruf vocal akhir kata). ${ }^{6}$ Kaidah-kaidah tersebut dapat tergambar dengan jelas pada tabel berikut:

\begin{tabular}{|l|l|l|l|l|}
\hline No & Nama Tembang & $\begin{array}{l}\text { Jumlah } \\
\text { Gatra }\end{array}$ & Wilangan & Dhongdhing \\
\hline 1. & Dhandhanggula & 10 & $10,10,8,7,9,7,6.8,12,7$ & $\mathrm{i}, \mathrm{a}, \mathrm{e}, \mathrm{u}, \mathrm{i}, \mathrm{a}, \mathrm{u}, \mathrm{a}, \mathrm{i}, \mathrm{a}$ \\
\hline 2. & Pangkur & 7 & $8,11,8,7,12,8,8$ & $\mathrm{a}, \mathrm{i}, \mathrm{u}, \mathrm{a}, \mathrm{u}, \mathrm{a}, \mathrm{i}$ \\
\hline 3. & Sinom & 9 & $8,8,8,8,7,8,7,8,12$ & $\mathrm{a}, \mathrm{i}, \mathrm{a}, \mathrm{i}, \mathrm{i}, \mathrm{u}, \mathrm{a}, \mathrm{i}, \mathrm{a}$ \\
\hline 4. & Durma & 7 & $12,7,6,7,8,5,7$ & $\mathrm{a}, \mathrm{i}, \mathrm{a}, \mathrm{a}, \mathrm{i}, \mathrm{a}, \mathrm{a}$ \\
\hline 5. & Asmaradana & 7 & $8,8,8,8,7,8,8$ & $\mathrm{i}, \mathrm{a}, \mathrm{e}, \mathrm{a}, \mathrm{a}, \mathrm{u}, \mathrm{a}$ \\
\hline 6. & Kinanthi & 6 & $8,8,8,8,8,8$ & $\mathrm{u}, \mathrm{i}, \mathrm{a}, \mathrm{i}, \mathrm{a}, \mathrm{i}$ \\
\hline 7. & Gambuh & 5 & $7,10,12,8,8$ & $\mathrm{u}, \mathrm{u}, \mathrm{i}, \mathrm{u}, \mathrm{o}$ \\
\hline 8. & Mijil & 6 & $10,6,10,10,6,6$ & $\mathrm{i}, \mathrm{o}, \mathrm{e}, \mathrm{i}, \mathrm{i}, \mathrm{u}$ \\
\hline
\end{tabular}

\footnotetext{
${ }^{5}$ Agus Sunyoto, Atlas Wali Songo (Jakarta: Pustaka Ilman, 2016), hlm. 159.

${ }^{6}$ Lutfianto. "Babad Demak Suntingan Teks, Terjemahan dan Analisis Struktur Naratif Episode Perjalanan Cerita Pandanarang dalam Memeluk Agama Islam Pupuh XXXVII-XXXIX". Thesis Interdiciplinary Islamic StudiesKonsentrasi Islam Nusantara Pascasarjana UIN Sunan Kalijaga Yogyakarta (2018).
} 


\begin{tabular}{|l|l|l|l|l|}
\hline 9. & Maskumambang & 4 & $12,6,8,8$ & $\mathrm{i}, \mathrm{a}, \mathrm{i}, \mathrm{a}$ \\
\hline 10. & Megatruh & 5 & $12,8,8,8,8$ & $\mathrm{u}, \mathrm{i}, \mathrm{u}, \mathrm{i}, \mathrm{o}$ \\
\hline 11. & Pucung & 4 & $12,6,8,12$ & $\mathrm{u}, \mathrm{a}, \mathrm{i}, \mathrm{a}$ \\
\hline
\end{tabular}

\section{TARJAMAH AL-QURAN DENGAN PENDEKATAN MACAPAT}

Beberapa ayat Al-Quran terjemahan tembang macapat akan dijabarkan sebagai berikut.

a. Tarjamah Al-Quran Tembang Pangkur

Padha gegondhèlan sira

Gegondhèlan Allah talining iki,

sarta aja tansah nesu

eling pêparing Allah

durung Islam paduka memungsub-mungsub

Allah yen nresnani sira

Dulur-dulur rak ya asib

Tarjamah Al-Quran Surat Ali- Imran ayat 103 dengan tembang Pangkur mempunyai jumlah larik/ gatra sebanyak tujuh larik. Setiap larik mempunyai jumlah suku kata/ wilangandan dhong-dhing (persajakan/ huruf vocal akhir kata)sebagai berikut:

\begin{tabular}{|l|l|l|l|}
\hline $\begin{array}{c}\text { Larik } \\
\text { ke- }\end{array}$ & \multicolumn{1}{|c|}{ Cakepan/Syair } & $\begin{array}{c}\text { Jumlah Suku } \\
\text { Kata/ } \\
\text { Wilangan }\end{array}$ & $\begin{array}{l}\text { Dhongdhing/ } \\
\text { Persajakan/ } \\
\text { Huruf } \\
\text { Vocal } \\
\text { Akhir Kata }\end{array}$ \\
\hline 1 & Padha gegondhèlan sira & 8 & $\mathrm{~A}$ \\
\hline 2 & Gegondhèlan Allah talining iki, & 11 & $\mathrm{I}$ \\
\hline 3 & sarta aja tansah nesu & 8 & $\mathrm{U}$ \\
\hline 4 & eling pêparing Allah & 7 & $\mathrm{~A}$ \\
\hline 5 & durung Islam paduka memungsub-mungsuh & 12 & $\mathrm{U}$ \\
\hline 6 & Allah yen nresnani sira & 8 & $\mathrm{~A}$ \\
\hline 7 & Dulur-dulur rak ya asih & 8 & $\mathrm{I}$ \\
\hline
\end{tabular}


Prayogane ana sira

padha nuntun marang bebêcik iki

padha akon gawe ayu

laku panggawe tata

apadene nyêgaha panggawe satru

wong kang mangkono ika

têtêp padha bêgja mukti

Tarjamah Al-Quran Surat Ali Imran ayat 104 dengan tembang Pangkur mempunyai jumlah larik/gatra sebanyak tujuh larik. Setiap larik mempunyai jumlah suku kata/wilangan dan dhong-dhing (persajakan/ huruf vocal akhir kata) sebagai berikut:

\begin{tabular}{|l|l|l|l|}
\hline $\begin{array}{c}\text { Larik } \\
\text { ke- }\end{array}$ & \multicolumn{1}{|c|}{ Cakepan/Syair } & $\begin{array}{c}\text { Jumlah Suku } \\
\text { Kata/ } \\
\text { Wilangan }\end{array}$ & $\begin{array}{l}\text { Dhongdhing/ } \\
\text { Persajakan/ } \\
\text { Huruf } \\
\text { Vocal } \\
\text { Akhir Kata }\end{array}$ \\
\hline 1 & Prayogane ana sira & 8 & $\mathrm{~A}$ \\
\hline 2 & padha nuntun marang bebêcik iki & 11 & $\mathrm{I}$ \\
\hline 3 & padha akon gawe ayu & 8 & $\mathrm{U}$ \\
\hline 4 & laku panggawe tata & 7 & $\mathrm{a}$ \\
\hline 5 & apadene nyêgaha panggawe satru & 12 & $\mathrm{u}$ \\
\hline 6 & wong kang mangkono ika & 8 & $\mathrm{a}$ \\
\hline 7 & têtêp padha bêgja mukti & 8 & $\mathrm{i}$ \\
\hline
\end{tabular}

b. Tarjamah Al-Quran Tembang Maskumambang

He wong mukmin, sira kabeh kudu bekti

Bektiya mring Allah

Aja padha sira mati

Kejaba mati ing Islam

Tarjamah Al-Quran Surat Ali Imran ayat 102 dengan tembang Maskumambang mempunyai jumlah larik/gatra sebanyak empat larik. Setiap larik mempunyai jumlah suku kata/wilangan dan dhong-dhing (persajakan/ huruf vocal akhir kata) sebagai berikut: 


\begin{tabular}{|l|l|l|l|}
\hline $\begin{array}{c}\text { Larik } \\
\text { ke- }\end{array}$ & \multicolumn{1}{|c|}{ Cakepan/Syair } & $\begin{array}{c}\text { Jumlah Suku } \\
\text { Kata/ } \\
\text { Wilangan }\end{array}$ & $\begin{array}{c}\text { Dhongdhing/ } \\
\text { Persajakan/ } \\
\text { Huruf } \\
\text { Vocal } \\
\text { Akhir Kata }\end{array}$ \\
\hline 1 & He wong mukmin, sira kabeh kudu bekti & 12 & I \\
\hline 2 & Bektiya mring Allah & 6 & A \\
\hline 3 & Aja padha sira mati & 8 & I \\
\hline 4 & Kejaba mati ing Islam & 8 & A \\
\hline
\end{tabular}

He wong mukmin, sira kabeh kudu bekti

ngestokna mring Allah

uga marang kanjeng Nabi

sarta wong ingkang kuwasa

Tarjamah Al-Quran Surat An-Nisa ayat 59 dengan tembang Maskumambang mempunyai jumlah larik/ gatra sebanyak empat larik. Setiap larik mempunyai jumlah suku kata/ wilangan dan dhong-dhing (persajakan/ huruf vocal akhir kata) sebagai berikut:

\begin{tabular}{|l|l|l|l|}
\hline $\begin{array}{c}\text { Larik } \\
\text { ke- }\end{array}$ & \multicolumn{1}{|c|}{ Cakepan/Syair } & $\begin{array}{c}\text { Jumlah Suku } \\
\text { Kata/ } \\
\text { Wilangan }\end{array}$ & $\begin{array}{c}\text { Dhongdhing/ } \\
\text { Persajakan/ } \\
\text { Huruf } \\
\text { Vocal } \\
\text { Akhir Kata }\end{array}$ \\
\hline 1 & He wong mukmin, sira kabeh kudu bekti & 12 & I \\
\hline 2 & ngestokna mring Allah & 6 & A \\
\hline 3 & uga marang kanjeng Nabi & 8 & I \\
\hline 4 & sarta wong ingkang kuwasa & 8 & A \\
\hline
\end{tabular}

He wong mukmin, sira mlêbu Islam iki 


\section{Mesthi kudu kaffah \\ aja manut setan iki \\ setan iki satrunira.}

Tarjamah Al-Quran Surat Al-Baqarah ayat 208 dengan tembang Maskumambang mempunyai jumlah larik/gatra sebanyak empat larik. Setiap larik mempunyai jumlah suku kata/wilangan dan dhong-dhing (persajakan/ huruf vocal akhir kata) sebagai berikut:

\begin{tabular}{|l|l|l|l|}
\hline $\begin{array}{c}\text { Larik } \\
\text { ke- }\end{array}$ & \multicolumn{1}{|c|}{ Cakepan/Syair } & $\begin{array}{c}\text { Jumlah Suku } \\
\text { Kata/ } \\
\text { Wilangan }\end{array}$ & $\begin{array}{l}\text { Dhongdhing/ } \\
\text { Persajakan/ } \\
\text { Huruf } \\
\text { Vocal } \\
\text { Akhir Kata }\end{array}$ \\
\hline 1 & He wong mukmin, sira mlébu Islam iki & 12 & I \\
\hline 2 & Mesthi kudu kaffah & 6 & A \\
\hline 3 & aja manut setan iki & 8 & I \\
\hline 4 & setan iki satrunira & 8 & A \\
\hline
\end{tabular}

Prayogane ana sagolongan siji

Nuntun mring agama

lan akon tumindak becik

nyegah ala padha begja

Tarjamah Al-Quran Surat Ali-imran ayat 110 dengan tembang Maskumambang mempunyai jumlah larik/gatra sebanyak empat larik. Setiap larik mempunyai jumlah suku kata/wilangan dan dhong-dhing (persajakan/ huruf vocal akhir kata) sebagai berikut:

\begin{tabular}{|l|l|l|l|}
\hline $\begin{array}{c}\text { Larik } \\
\text { ke- }\end{array}$ & \multicolumn{1}{|c|}{ Cakepan/Syair } & $\begin{array}{c}\text { Jumlah suku } \\
\text { Kata/ } \\
\text { Wilangan }\end{array}$ & $\begin{array}{c}\text { Dhongdhing/ } \\
\text { Persajakan/ } \\
\text { Huruf } \\
\text { Vocal } \\
\text { Akhir Kata }\end{array}$ \\
\hline 1 & Prayogane ana sagolongan siji & 12 & $\mathrm{i}$ \\
\hline 2 & Nuntun mring agama & 6 & $\mathrm{a}$ \\
\hline
\end{tabular}




\begin{tabular}{|l|l|l|l|}
\hline 3 & lan akon tumindak becik & 8 & $\mathrm{i}$ \\
\hline 4 & nyegah ala padha begja & 8 & $\mathrm{a}$ \\
\hline
\end{tabular}

\section{PENUTUP}

Wayang Kekayon Khalifah Yogyakarta menghadirkan cerita yang bersumber dari Islam. Al-Quran sebagai sumber ajaran Islam tertulis dalam sastra yang indah, dalam Wayang Kekayon Khalifah ayat-ayatnya diterjemahkan dalam sastra Jawa tembang macapat. Tembang macapat yang dipakai antara lain adalah tembang Pangkur dan Maskumambang. Pendekatan terjemahan dengan macapat ini untuk mendialogkan sastra Arab yang ada di dalam Al-Quran dengan sastra Jawa yang tertuang dalam tembang Macapat. Dengan terjemahan seperti ini bertujuan untuk menyampaikan ajaran Islam yang terdapat dalam Al-Quran dengan penuh hikmah. Sehingga masyarakat Jawa bisa menerima dengan baik tanpa harus meninggalkan sastra yang ia punya. 


\section{DAFTAR PUSTAKA}

Bandem, I Made dan Murgianto. (1999). Teater daerah di Indonesia . Yogyakarta: Kanisius.

Lutfianto. (2018). "Babad Demak Suntingan Teks, Terjemahan dan Analisis Struktur Naratif Episode Perjalanan Cerita Pandanarang dalam Memeluk Agama Islam Pupuh XXXVII-XXXIX'. Thesis Interdiciplinary Islamic Studies Konsentrasi Islam Nusantara Pascasarjana UIN Sunan Kalijaga Yogyakarta.

Monika Devi. (2018). “Wayang Kekayon Khalifah Yogyakarta”. Skripsi Program Studi Pendidikan Kriya Jurusan Pendidikan Seni Rupa Fakultas Bahasa dan Seni Universitas Negeri Yogyakarta.

Saifullah. (2010). Sejarah dan Kebudayaan Islam di Asia Tenggara. Yogyakarta: Pustaka Pelajar.

Sumarsam. (2018). Memaknai Wayang dan Gamelan: Temu Silang Jawa, Islam, dan Global. Yogyakarta: Gading.

Sunarto. (2012). Gendeng Dusun Kerajinan Wayang Kulit Purwa Yogyakarta Kelangsungan dan Perubahannya. Yogyakarta. Penerbit Lembaga Penelitian ISI Yogyakarta.

Sunyoto, Agus. (2016). Atlas Wali Songo. Jakarta: Pustaka Ilman.

Tim Senawangi. (1999). Ensiklopedi Wayang Indonesia. Jakarta. Penerbit Senawangi.

Zarkasi, Effendy. (1996). Unsur-Unsur Islam dalam Pewayangan; Telaah atas penghargaan Wali Sanga terhadap Wayang untuk media Da'wah Islam. Sala. Yayasan Mardikintoko. 